\title{
Filtration and Catalytic Behaviors of Titanium Silicate-1 Supported on Carbon Nanofibers for Cyclohexanone Ammoximation
}

\author{
Qian Zhao ${ }^{1,2}$, Shiyuan Zhang1, Ping Li1 ${ }^{1}$, Weikang Yuan ${ }^{1}$, \\ Alex Chikin Yip ${ }^{3}$ and Xijun $\mathrm{Hu}^{3}$ \\ ${ }^{1}$ State Key Laboratory of Chemical Engineering, East China University of \\ Science and Technology, Shanghai \\ ${ }^{2}$ Department of Chemical Engineering and Technology, \\ Hebei University of Technology, Tianjin \\ ${ }^{3}$ Department of Chemical Engineering, Hong Kong University of \\ Science and Technology, Hong Kong \\ P. R. China
}

\section{Introduction}

Titanium silicalite-1 (TS-1), a MFI structure zeolite, is exclusively used as the catalyst in cyclohexanone ammoximation for its extremely high catalytic activity and selectivity.1,2 It has been proved that the active sites inside the microporous channels of TS- 1 are easily accessible to reactants when the particle size is controlled in a range of $200-300 \mathrm{~nm}$. However, the separation of the nanosized TS- 1 from liquid reaction systems by filtration is very difficult in industrial applications. ${ }^{3}$ To deal with this problem, efforts have been made to immobilize TS-1 crystallites on supports with relatively large dimensions so as to facilitate the filtration. ${ }^{4-7}$ Nevertheless, the dissolution of oxide supports such as $\mathrm{A}_{2}{ }_{2} \mathrm{O}_{3}$ and $\mathrm{SiO}_{2}$ during TS-1 synthesis can result in a structural change of TS- 1 crystallites and consequently a low utilization efficiency of $\mathrm{H}_{2} \mathrm{O}_{2}$ in reaction. ${ }^{4-6}$ Carbon materials such as active carbon and graphite can be excellent candidates for support because of their chemical inertness to the reaction. But the separation performance of the TS-1/carbon composites has rarely been reported yet. ${ }^{7}$

Carbon nanofibers $(\mathrm{CNFs})^{8-11}$ have been attracting extensive interests owing to their large external surface and few micropores, chemical inertness and hybrid electronic structure. In particular, their high mechanical strength and long filamentary modality are beneficial for them to tolerating vigorous agitation in slurry systems. Furthermore, they can be facilely filtrated from the slurry. ${ }^{8}$ Therefore, CNFs was deliberately selected as the support for TS-1 immobilizing. 12

In this paper, TS-1/CNFs composite catalysts were synthesized by in situ crystallization and simple mechanical blending methods, respectively. The catalytic behaviors and filtration performance of TS-1/CNFs were examined in cyclohexanone ammoximation. The structure of catalyst is characterized using techniques including SEM, XRD, FT-IR, UV-Vis, Raman and XRF spectroscopy. The aim of the study is to develop a composite TS-1/CNFs catalyst 
which can be easily separated from the slurry system without compromising the catalytic activity and the selectivity.

\section{Experimental}

\subsection{Synthesis}

\subsubsection{Synthesis of CNFs}

CNFs were grown on a Fe catalyst at $600{ }^{\circ} \mathrm{C}$ by a chemical vapor deposition (CVD) method using $\mathrm{CO}$ as carbon source. ${ }^{12}$ The CNFs as grown were then immersed in a $4 \mathrm{M} \mathrm{HCl}$ solution at $60{ }^{\circ} \mathrm{C}$ under stirring for $2 \mathrm{~h}$ so as to dissolve Fe particles. Subsequently, the $\mathrm{CNF}$ s suspending was filtered and the CNFs on the filter medium were washed with copious deionized water. After triply filtering and washing, the purified CNFs were finally dried at $120{ }^{\circ} \mathrm{C}$ overnight. The final CNFs contained less than 0.1 wt \% Fe as detected by means of inductively coupled plasma spectroscopy (ICP, Optima 2100 DV, PerkinElmer Instruments).

\subsubsection{Synthesis of TS-1}

Firstly, tetraethyl orthosilicate (TEOS) was added to tetrapropyl ammonium hydroxide (TPAOH) with vigorously stirring. Then, a tetrabutyl orthotitanate (TBOT) solution (in isopropanol) was brought dropwise into the above mixture. The resulting solution was aged at $80{ }^{\circ} \mathrm{C}$ for $5 \mathrm{~h}$. A typical molar composition of the final gel was set to $\mathrm{SiO}_{2}: \mathrm{TiO}_{2}$ : TPAOH: $\mathrm{H}_{2} \mathrm{O}=1: 0.025: 0.3: 20$, corresponding to a $\mathrm{Si} / \mathrm{Ti}$ molar ratio of 40 . Next, the gel was transferred into an autoclave for crystallization at $175{ }^{\circ} \mathrm{C}$ for $72 \mathrm{~h}$. After that, the cooled product was filtered and the solid product on the filter medium was washed with deionized water. Finally, the solid product was dried at $120{ }^{\circ} \mathrm{C}$ for $12 \mathrm{~h}$, followed by calcining in air or Ar atmosphere at $550{ }^{\circ} \mathrm{C}$ for $6 \mathrm{~h}$ to eliminate $\mathrm{TPAOH}$.

\subsubsection{Preparation of blended TS-1/CNFs composite}

TS- 1 crystallites and the CNFs powder were mechanically mixed with deionized water at room temperature. After $24 \mathrm{~h}$ agitation, the mixture was then filtered and the solid TS$1 / \mathrm{CNFs}$ was dried at $120^{\circ} \mathrm{C}$ for $12 \mathrm{~h}$. The weight ratio of TS- 1 to CNFs in the TS- $1 / \mathrm{CNFs}$ composite was kept at 2 .

\subsubsection{Preparation of in situ crystallized TS-1/CNFs composite}

The procedure for the preparation of in situ crystallized TS-1/CNFs composite is almost the same as that for the synthesis of TS-1, with the exception of the addition of CNFs into the colloid before hydrothermal treatment at $175{ }^{\circ} \mathrm{C}$. TS- $1 / \mathrm{CNF}$ were calcined in $\mathrm{Ar}$ at $550{ }^{\circ} \mathrm{C}$ for $6 \mathrm{~h}$. The weight ratio of TS-1 to CNFs was also regulated to 2. For the synthesis of composites with different $\mathrm{Si} / \mathrm{Ti}$ ratios, the amount of $\mathrm{TiO}_{2}$ in the gel was adjusted on the basis of $\mathrm{SiO}_{2}$.

\subsection{Characterization}

Material morphology observations were executed on a JEOL JSM-6360LV scanning electron microscope (SEM). X-ray diffraction (XRD) patterns of material solid phase composition were recorded in a $2 \theta$ range $5^{\circ} \sim 80^{\circ}$ using a Rigaku D/Max 2550VB/PC diffractometer equipped with a $\mathrm{Cu} / \mathrm{K}_{\alpha}$ radiation source $(\lambda=0.154056 \mathrm{~nm})$ and operated at a voltage of 40 
$\mathrm{kV}$ and a current of $100 \mathrm{~mA}$. Infrared (IR) spectra of material were acquired on a Bruker Equinox-55 FT-IR spectrometer ( $\mathrm{KBr}$ plate). Diffuse reflectance ultraviolet-visible spectrometry (UV-Vis, Varian Cary-500 spectrometer) was performed in a range 200 800 $\mathrm{nm}$ using Si-1 zeolite as the reference. Laser Raman spectra (Renishaw inVia-Reflex spectrometer) were taken with an $\mathrm{Ar}^{+}$laser beam tuned at $514 \mathrm{~nm}$ radiation wavelength. Material composition was detected on an X-ray fluorescence spectrometer (XRF-1800, Shimadzu Corporation).

\subsection{Evaluation of catalytic performance of catalyst}

Batch-wise cyclohexanone ammoximation was performed to evaluate the catalytic activity and selectivity. The reaction was carried out in a three-neck flask fitted with a stirrer, a condenser and a feed pump. The catalyst of $1.125 \mathrm{~g}$ TS-1/CNFs composite (TS-1: CNFs $=2$ in weight) or $0.750 \mathrm{~g}$ TS-1 or $0.375 \mathrm{~g}$ CNFs was dispersed into a mixture of $5 \mathrm{~g}$ cyclohexanone, $12.5 \mathrm{ml}$ t-butanol and $12.5 \mathrm{ml} \mathrm{H}_{2} \mathrm{O}$; and the flask was warmed in a water bath at $80{ }^{\circ} \mathrm{C}$. With turbulently agitating the mixture, $\mathrm{NH}_{3}(28 \mathrm{wt} \%)$ was injected into the flask with a dose every $30 \mathrm{~min}$ and $\mathrm{H}_{2} \mathrm{O}_{2}(30 \mathrm{wt} \%)$ was injected dropwise through the feed pump within $1.5 \mathrm{~h}$. The total molar ratio of cyclohexanone: $\mathrm{H}_{2} \mathrm{O}_{2}: \mathrm{NH}_{3}$ was 1: 1.4: 2 . After $2 \mathrm{~h}$ reaction, the cooled reaction slurry was then filtered and the filtrate was extracted with toluene. Both cyclohexanone oxime and the unreacted cyclohexanone in the extractive were analyzed by a gas chromatography (GC, HP-6890) equipped with a HP-5 capillary column. 1,3,5-trimethylbenzene was used as an internal standard substance.

The catalytic activity is defined as the conversion of cyclohexanone after reaction based on the weight of cyclohexanone in the feed, and the selectivity is the weight of cyclohexanone oxime produced on the basis of cyclohexanone converted.

\subsection{Evaluation of filtration performance of catalyst}

The filtration of the reaction slurry was managed with a constant velocity using an injecting pump while the particles in the slurry were passing through a composite fiber membrane with uniform pores of $1.2 \mu \mathrm{m}$. The filtration resistance was measured with a pressure gauge. The turbidity of filtrate, an indication of the amount of filterable particles, was tested by a nephelometer (turbidity unit: NTU, number of transfer unit).

\section{Results and discussion}

\subsection{Catalytic behaviors and filtration performance of CNFs, TS-1 and TS-1/CNFs}

As listed in Table 1, 47.3\% of cyclohexanone was converted but no cyclohexanone oxime was detected while using pure CNFs as the catalyst after $2 \mathrm{~h}$ reaction. In contrast, over the TS-1 crystallites, cyclohexanone was almost completely converted and the selectivity to oxime reached to ca. 95\%. A slight decline in oxime selectivity was observed on the TS-1 calcined in Ar than in air, probably due to the template residues emerging in inactive atmosphere which partly block the channels of TS-1.13,14 By comparing separately the blended TS-1/CNFs composite and the in situ crystallized one with pure TS- 1 in the catalytic performance, we can see that the former exhibited a higher activity and selectivity while the latter partly deactivated. The reasons will be anatomized hereinafter.

The filtration result of the slurry containing CNFs after reaction (Table 1) indicates almost no CNFs appearing in the filtrate. This is probably attributed to the unique morphology of 
CNFs (Fig. 1a). CNFs have a long filamentous appearance with ten $\mu \mathrm{m}$ in length and $250 \mathrm{~nm}$ in diameter. The curly and entangled CNF filaments agglomerated into granules with macroporous pores (Fig. 1a), and the granule size was distributed up to $100 \mu \mathrm{m}$ (Fig. 1b). The morphology of CNF granules remained in the reaction slurry having undergone $2 \mathrm{~h}$ vigorous stirring (Fig. 1c). The particle size distributions of the CNFs as grown and after ultrasonic treating for $2.5 \mathrm{~h}$ were measured by means of laser granularity analysis (Fig. 2). The result shows that the dominant particle size around $10 \mu \mathrm{m}$ was retained after treating. It is evident that the compact agglomeration of CNFs to large dimensions renders CNFs to be facilely intercepted by filter membrane and thus to be separated from the slurry after reaction.

\begin{tabular}{|c|c|c|c|c|c|}
\hline \multicolumn{2}{|c|}{ Catalytic material } & \multicolumn{2}{|c|}{ Catalytic activity and selectivity } & \multicolumn{2}{|c|}{ Filtration result after reaction } \\
\hline Description & $\begin{array}{l}\mathrm{Si} / \mathrm{Ti} \\
\text { in gel }\end{array}$ & $\begin{array}{l}\text { Cyclohexanone } \\
\text { conversion/\% }\end{array}$ & $\begin{array}{l}\text { Cyclohexanone } \\
\text { oxime } \\
\text { selectivity/\% }\end{array}$ & $\begin{array}{l}\text { Turbidity } \\
\text { of filtrate } \\
\text { /NTU }\end{array}$ & State of filtrate \\
\hline CNFs & - & 47.3 & 0 & 1 & Clear \\
\hline $\begin{array}{l}\text { TS-1 } \\
\text { calcined in air }\end{array}$ & 40 & 99.8 & 94.7 & 107 & $\begin{array}{l}\text { Plenty of white } \\
\text { particles suspending }\end{array}$ \\
\hline $\begin{array}{l}\text { TS-1 } \\
\text { calcined in Ar }\end{array}$ & 40 & 99.8 & 89.5 & 115 & $\begin{array}{l}\text { Plenty of white } \\
\text { particles suspending }\end{array}$ \\
\hline $\begin{array}{l}\text { Blended } \\
\text { TS-1/CNFs }\end{array}$ & 40 & 99.7 & 92.4 & 48 & $\begin{array}{l}\text { Few white particles } \\
\text { suspending }\end{array}$ \\
\hline $\begin{array}{l}\text { Blended } \\
\text { TS-1/CNFs after } \\
\text { CNFs removal }\end{array}$ & 40 & 98.9 & 94.9 & 112 & $\begin{array}{l}\text { Plenty of white } \\
\text { particles suspending }\end{array}$ \\
\hline $\begin{array}{l}\text { In-situ crystallized } \\
\text { TS-1/CNFs }\end{array}$ & 40 & 49.7 & 7.7 & 15 & Clear \\
\hline $\begin{array}{l}\text { In-situ crystallized } \\
\text { TS-1/CNFs after } \\
\text { CNFs removal }\end{array}$ & 40 & 49.0 & 8.0 & 124 & $\begin{array}{l}\text { Plenty of white } \\
\text { particles suspending }\end{array}$ \\
\hline $\begin{array}{l}\text { In-situ crystallized } \\
\text { TS-1/CNFs }\end{array}$ & 10 & 96.6 & 83.2 & 11 & Clear \\
\hline $\begin{array}{l}\text { In-situ crystallized } \\
\text { TS-1/CNFs }\end{array}$ & 5 & 92.1 & 78.4 & 4 & Clear \\
\hline
\end{tabular}

Table 1. Catalytic and filtration performance of CNFs, TS-1 and different TS-1/CNFs composites.

The filtration results of the TS-1 samples calcined in air and Ar were also listed in Table 1. The turbidity of the filtrate was relatively high for both samples because of many white particles suspending in the filtrate. The TS- 1 crystallites with tiny dimension and isolated sphere morphology (Fig. 1d) undoubtedly cause the penetration of white TS-1 particles into the filtrate.

Both TS-1/CNFs composites showed better filtration performance than pure TS-1 (Table 1). The low filtrate turbidity of the composites especially the in situ crystallized one indicates 
Filtration and Catalytic Behaviors of Titanium Silicate-1

the rarity of TS- 1 or CNFs particles in the filtrate. Clearly, the TS- 1 crystallites were scarcely detached from the composite during reaction, implying strong interactions between TS-1 and CNFs.

SEM images of both composites (Fig. 1e-f) illustrate large granules in congeries modality. Nevertheless, isolated TS-1 crystallites are difficult to be found, consistent with the observation of filtration performance. In the high magnification SEM images (Fig. 1g-h), the filamentous CNFs can be easily distinguished from the small TS- 1 particles by length. Spherical TS-1 crystallites are uniformly distributed among the network of intertwining CNFs in both composites. The TS-1 particles formed through in situ crystallized manner are of $200 \sim 300 \mathrm{~nm}$ in diameter, which is comparable to that of pure TS- 1 assembled in the blended composite. As pointed out in our previous study, ${ }^{15}$ a surface electrostatic effect may exist between TS-1 and CNFs, playing an important role in cohesion of two materials. Furthermore, intensified molecular forces resulting from nano-size effect of two materials may also contribute to the enhanced adhesion of individual TS-1 particles on the surface of CNF filaments. For the in situ crystallized TS-1/CNFs composite, the surface oxygenous functional groups on $\mathrm{CNFs}^{16}$ may favor the chemical interaction between CNFs and in situ generated TS-1 crystallites via oxygen bridges. Thus, the intra-action among the in situ crystallized composite may be stronger than that of the blended one.
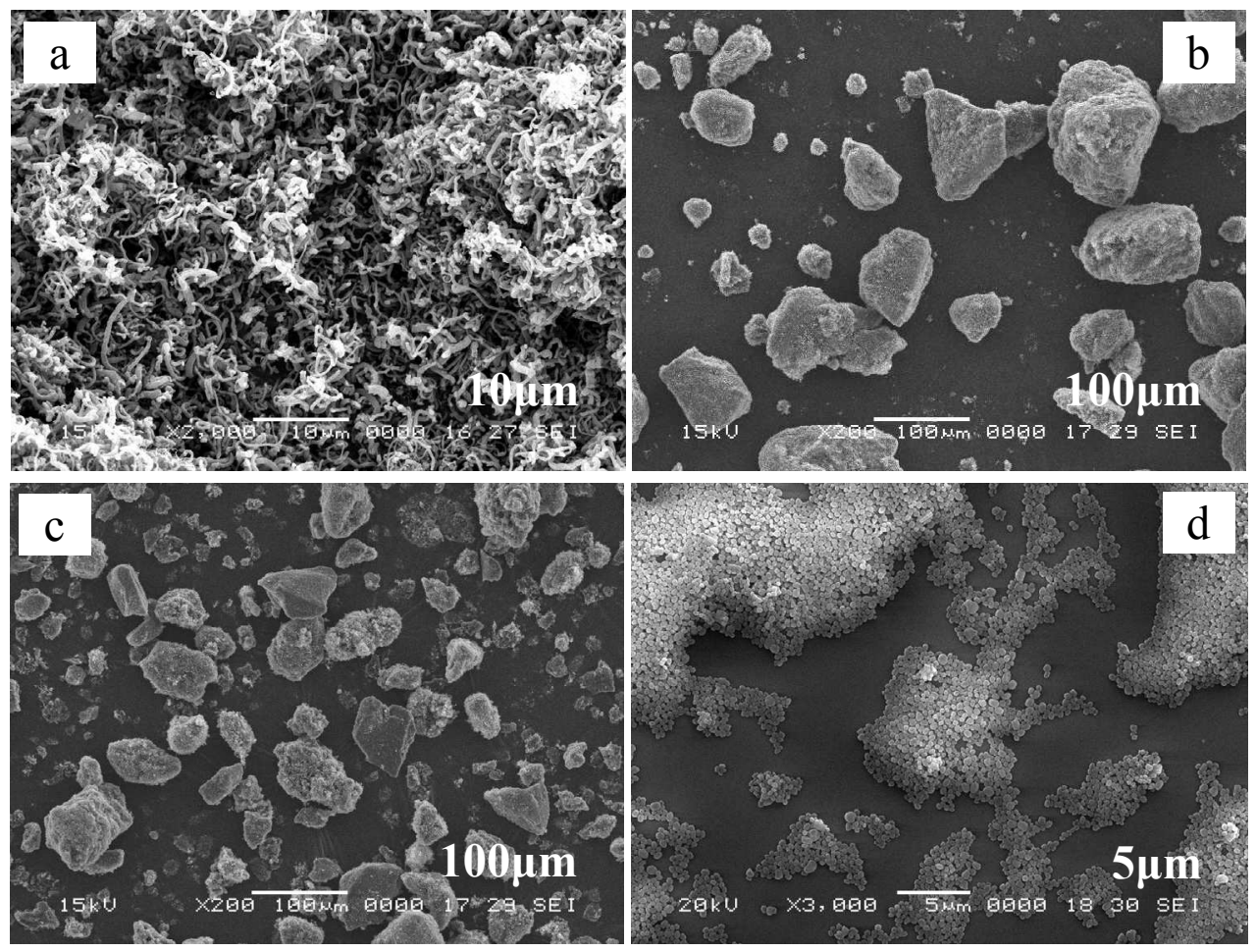

Fig. 1. Continued 

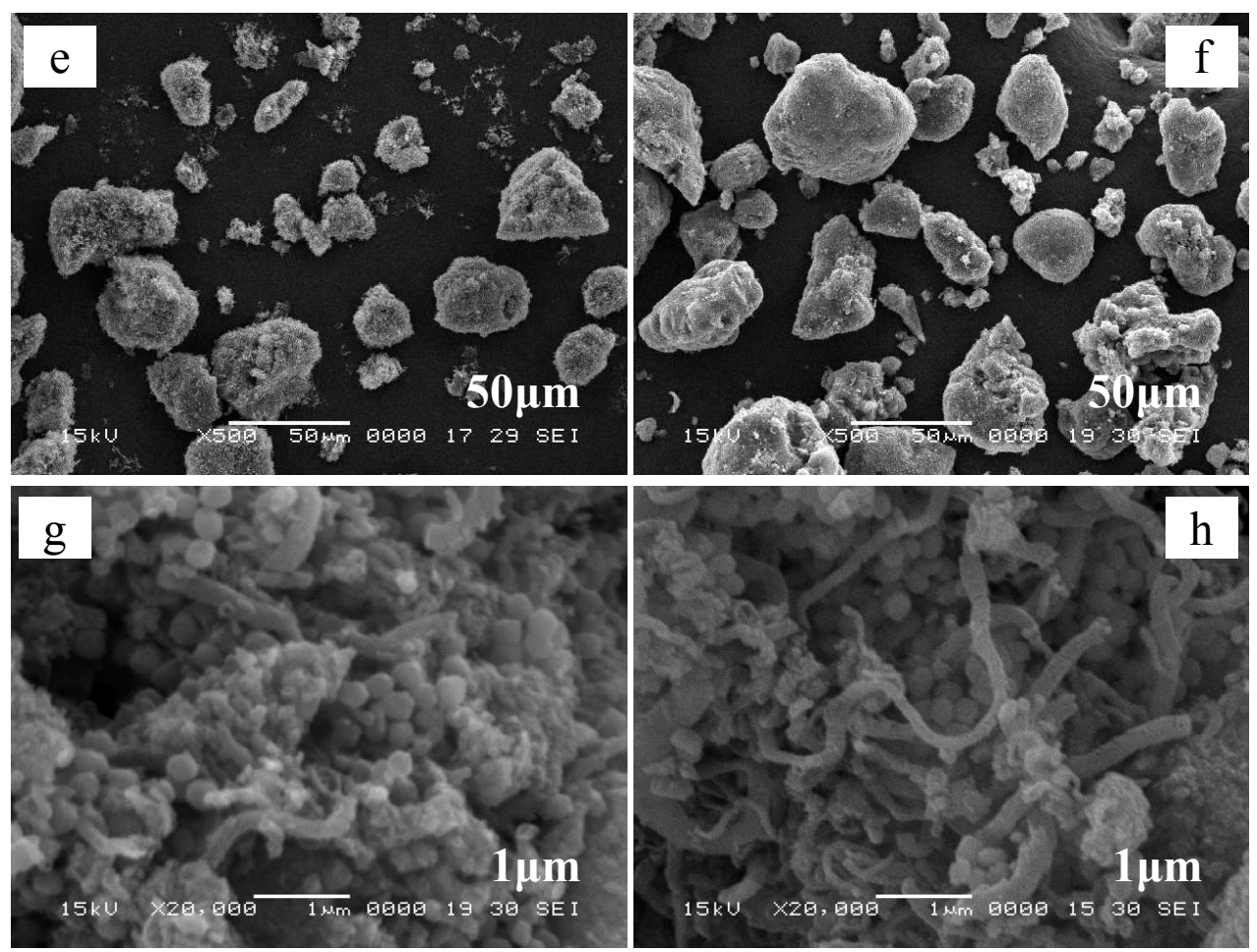

Fig. 1. SEM images of CNFs, TS-1 and TS-1/CNFs composites.

(a) CNFs; (b) CNF agglomerates; (c) CNF agglomerates after reaction; (d) TS-1; (e) Blended TS-1/CNFs composite agglomerates; (f) In situ crystallized TS-1/CNFs composite agglomerates; (g) Blended TS-1/CNFs composite (high magnification); (h) In situ crystallized TS-1/CNFs composite (high magnification).

The change in the resistance with time during slurry filtration under a constant velocity is demonstrated in Fig. 3. Extremely low resistance was undergone while filtrating the slurry containing CNFs. This manifests that the CNFs forming agglomerates with large size and macroporous pores can prevent them from blocking the filter membrane and the cake formed afterwards.17,18 From the curve of TS-1, we can see that the filtration resistance increases rapidly right from the beginning owing to the blockage of the filter membrane by the tiny TS- 1 crystallites. In comparison with the case involving pure TS-1, a significant decrease in the resistance was found during the filtration of slurry containing TS-1/CNFs composite, especially the in situ crystallized one. It is obvious that the filtration behavior of the composites is more similar to that of CNFs rather than TS-1. As having been known, a filter aid can render the cake configured highly porous, thereby facilitating the filtration process. ${ }^{17}$ In view of this, the role of CNFs playing in the composites is a kind of filter aid in addition to the support of TS-1. Taking into consideration the network structure of the composites and the substantial affinity between two components, the excellent filtration performance of both TS-1/CNFs composites can be understandable. 


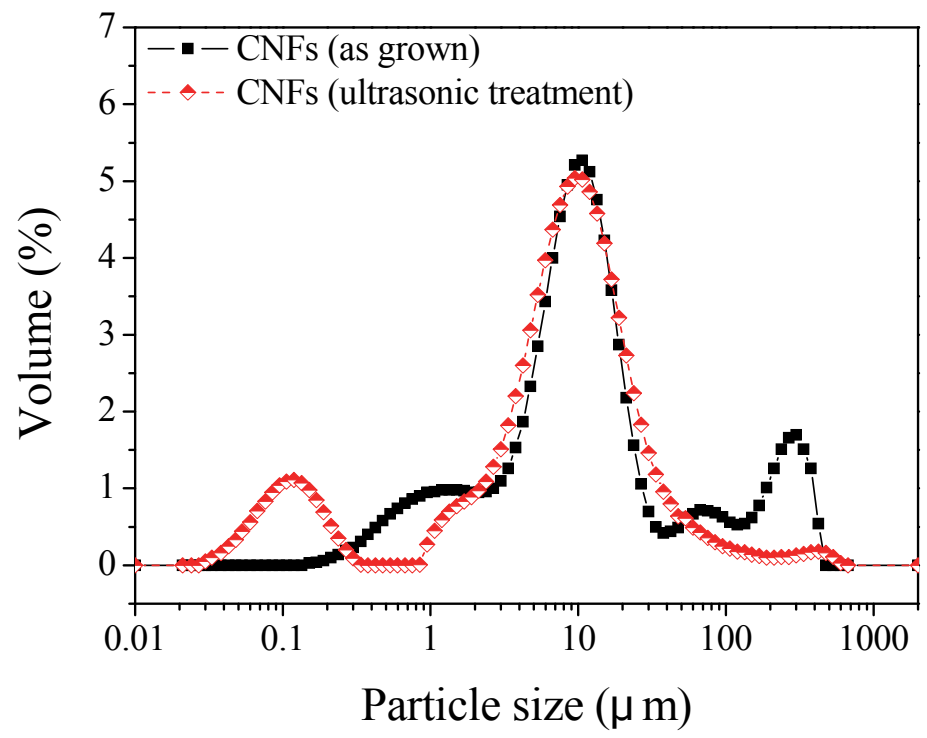

Fig. 2. Particle size distribution of CNFs as grown and after ultrasonic treatment.

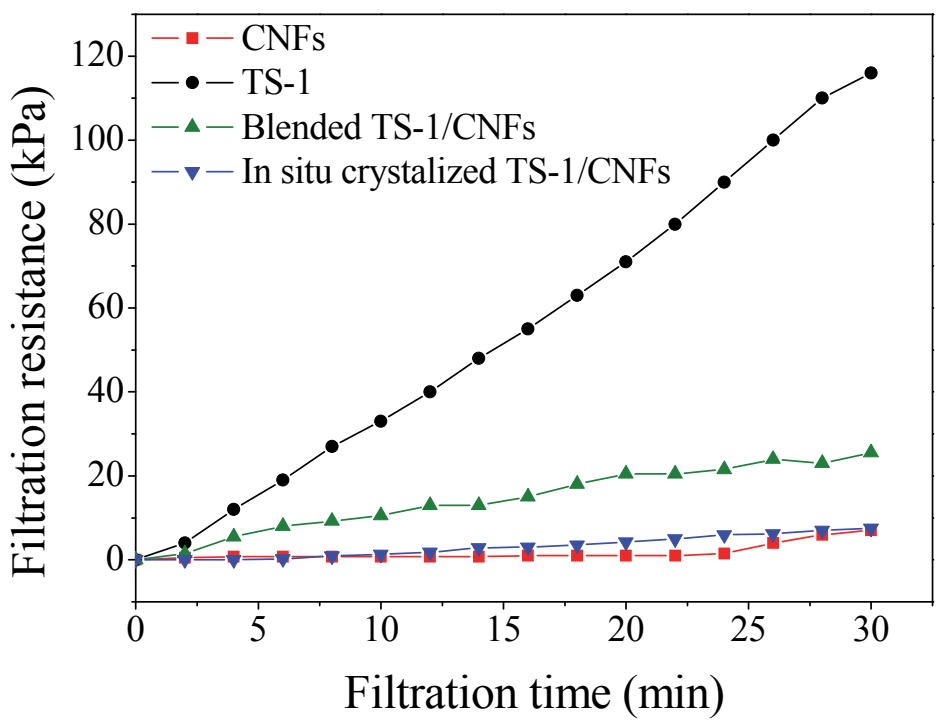

Fig. 3. Change in filtration resistance of different materials with filtration time. 


\subsection{TS-1 structures of the blended and the in situ crystallized TS-1/CNFs composites}

As described above, the catalytic behaviors of pure TS- 1 are basically preserved in the TS$1 / \mathrm{CNF}$ composite prepared by simple mechanical blending. Only a slight decrease in selectivity was detected, being ascribed to the unselective decomposition of $\mathrm{H}_{2} \mathrm{O}_{2}$ induced by CNFs. Hence, we deduce that the interference of CNFs in the reaction is very weak. On the other hand, it is known that the catalytic behaviors of TS-1 depend on the content of lattice $\mathrm{Ti}$ in tetrahedral coordination, and the incorporation of $\mathrm{Ti}$ into the framework of zeolite generally occurs in the crystallization process. ${ }^{19,20}$ However, the non-framework $\mathrm{Ti}$ species, such as octahedral Ti species and Ti oxides, are inactive for this type of selective oxidation reaction. ${ }^{20-24}$ Therefore, with respect to the in situ crystallized TS-1/CNFs composite, its inferior catalytic performance is perhaps due to the change in Ti coordination states.

The structure of TS-1 for both composite samples was studied using XRD, FT-IR, UV-Vis, and Raman spectroscopy. However, owing to the strong optical adsorption and disturbance of the coexisting CNFs, the characteristics of TS-1 in the composite were difficult to identify. ${ }^{12}$ In our measurements, in order to improve the quality of spectroscopy, the CNFs in the composite were removed by burning off carefully in air with a ramp rate of $2 \circ \mathrm{C} / \mathrm{min}$ to $550{ }^{\circ} \mathrm{C}$ for $6 \mathrm{~h}$. In fact, oxidative calcination at high temperatures was generally adopted in TS-1 synthesis for template elimination, 19,25,26 in spite of the fact that the decrease in defect sites of titanium silicate material and the ejection of Ti framework species occur with the rise of temperature. 13,27

XRD patterns show (Fig. 4) the diffraction peaks appearing at $2 \theta=7.8^{\circ}, 8.8^{\circ}, 23.1^{\circ}, 23.9^{\circ}$, $24.4^{\circ}$ and $29.2^{\circ}$. These peaks are the characteristics of the typical MFI structure of zeolite, and two single reflection peaks at $24.4^{\circ}$ and $29.2^{\circ}$, respectively, are an indicative of the presence of $\mathrm{Ti}$ in the framework. ${ }^{28} \mathrm{TiO}_{2}$ (anatase) may not exist because the corresponding peaks $\left(2 \theta=25.4^{\circ}, 37.8^{\circ}\right.$, and $\left.48.0^{\circ}\right)$ weren't detected. Moreover, almost no difference between two XRD patterns of both samples implies a considerable homology of the TS-1 crystalline structure in two composites.

The FT-IR spectra (Fig. 5) show a strong band at $1100 \mathrm{~cm}^{-1}$ assigned to asymmetric Si-O-Si stretching vibration, a symmetric vibration at $800 \mathrm{~cm}^{-1}$ and a bending vibration at $450 \mathrm{~cm}^{-1}$. The second strong band at $550 \mathrm{~cm}^{-1}$ is related to the lattice vibration of zeolite MFI structure. ${ }^{12}$ The band at $960 \mathrm{~cm}^{-1}$ is a diagnostic character of $\mathrm{Ti}$ incorporation to zeolite framework and quantitatively associated with Ti content in tetrahedral coordination. 19,29 The infrared spectra of two TS-1 samples derived from different composites are nearly identical with the exception of the intensity of $960 \mathrm{~cm}^{-1}$ band. The in situ crystallized TS-1 sample has lower intensity of $960 \mathrm{~cm}^{-1}$ band than the blended one.

In UV-Vis spectrum, a band around $210 \mathrm{~nm}$ is generally assigned to the isolated tetrahedral Ti species in the framework. ${ }^{30,31}$ Anatase $\mathrm{TiO}_{2}$ can be identified by a band around 330 $\mathrm{nm} .{ }^{21,32}$ In addition, the band at $280 \mathrm{~nm}$ is assigned to the partially condensed hexacoordinated Ti species (extra-framework Ti). ${ }^{24,33}$ After removing CNFs, the UV-Vis spectra of TS-1/CNFs were recorded with referring Si-1 (Fig. 6). The TS-1 of the blended composite exhibits a main band at $220 \mathrm{~nm}$ with a weak band at $280 \mathrm{~nm}$. No specific band around 330 $\mathrm{nm}$ can be perceived. In contrast, the bands at 220, 280 and $330 \mathrm{~nm}$ in the spectrum recorded for the in situ crystallized TS-1 indicates the formation of extra-framework Ti and anataselike species. 


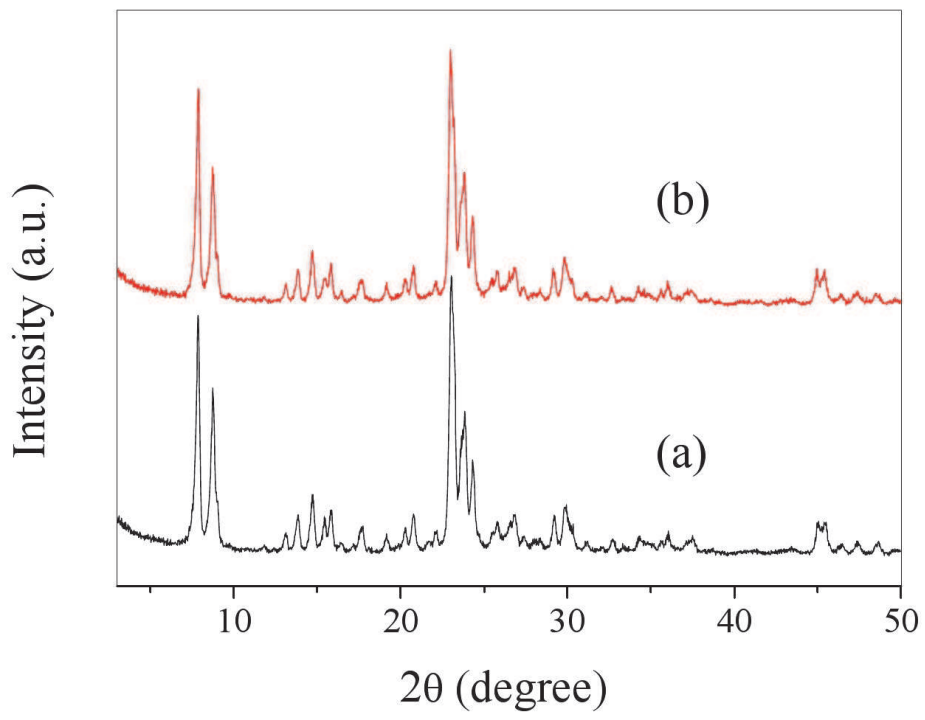

Fig. 4. XRD patterns of TS-1/CNFs composites after removing CNFs.

(a) Blended TS-1/CNFs (Si/Ti=40); (b) In-situ crystallized TS-1/CNFs (Si/Ti=40).

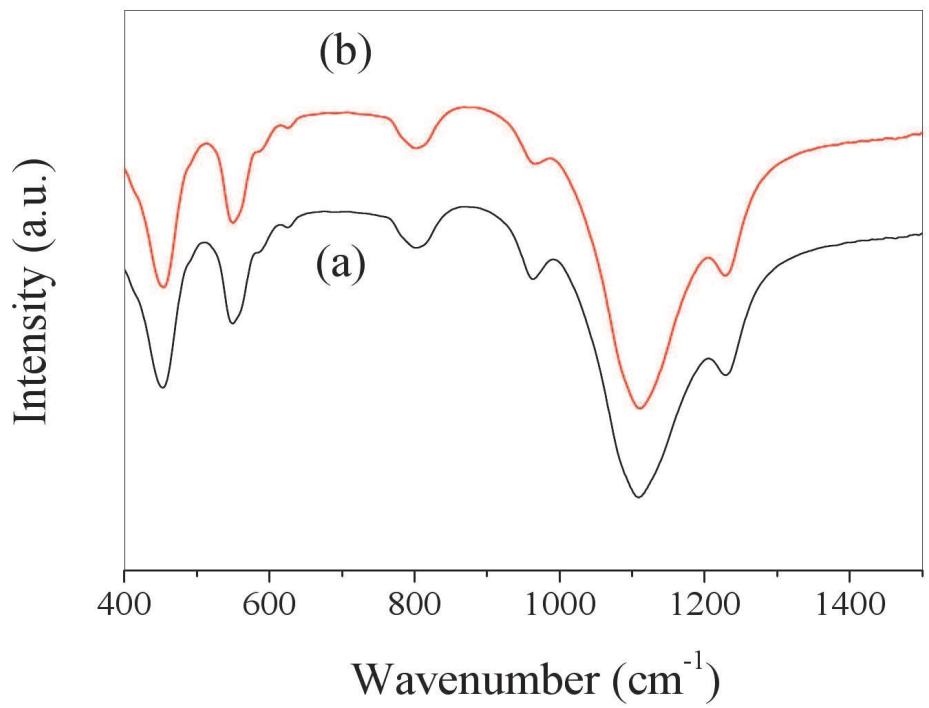

Fig. 5. FT-IR spectra of TS-1/CNFs composites after removing CNFs.

(a) Blended TS-1/CNFs (Si/Ti=40); (b) In-situ crystallized TS-1/CNFs (Si/Ti=40). 


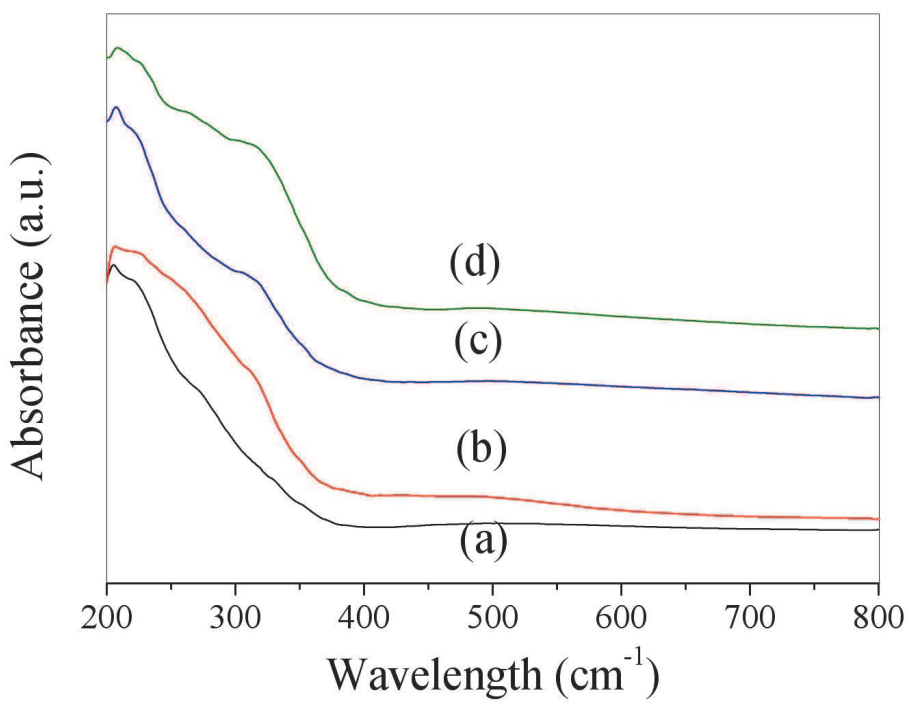

Fig. 6. UV-Vis spectra of TS-1/CNF composites after removing CNFs.

(a) Blended TS-1/CNFs (Si/Ti=40); (b) In-situ crystallized TS-1/CNFs (Si/Ti=40);

(c) In-situ crystallized TS-1/CNFs ( $\mathrm{Si} / \mathrm{Ti}=10)$; (d) In-situ crystallized TS-1/CNFs (Si/Ti=5).

The Raman spectrum (Fig. 7) of TS-1 in the blended TS-1/CNFs shows bands at 290, 375, $467,800-830,960,1090$ and $1128 \mathrm{~cm}^{-1}$, respectively, corresponding to the typical structure of TS-1.34 The bands at 960 and $1128 \mathrm{~cm}^{-1}$, assigned to the asymmetric and symmetric stretching vibrations of $\mathrm{TiO}_{4}$ tetrahedron, may be resulted from Ti incorporation to zeolite framework. $29,34,35$ In the Raman spectrum of the in situ crystallized TS-1/CNFs, besides the typical bands of TS-1 described above, distinct bands are present at 397, 515 and $638 \mathrm{~cm}^{-1}$, which are characteristics of anatase particles. ${ }^{35}$

It has been reported that there are numerous simultaneous and independent equilibria of nucleation and crystal growth during TS- 1 crystallization. Meanwhile, there is a competition of Ti ions bonding to the framework with those aggregating to metal oxides. The presence of structure-breaking agents in the synthesis gel can impair the sufficiency of $\mathrm{Ti}$ incorporation. ${ }^{21,24}$ In the present work, the CNFs with positive-charged surface might induce the sequential adsorption and condensation of negative Ti-OH groups onto them, ${ }^{17}$ hence disturbing the oriental isomorphous substitution of $\mathrm{Ti}$ for $\mathrm{Si}$. As a result, the non-framework $\mathrm{Ti}$ species formed and the lattice $\mathrm{Ti}$ content decreased, leading to inferior catalytic performance of the in situ crystallized TS-1/CNFs composite.

\subsection{Catalytic and filtration performance of in situ crystallized TS-1/CNFs composites with different $\mathrm{Si} / \mathrm{Ti}$ ratios}

As listed in Table 1, both cyclohexanone conversion and oxime selectivity were increased with a decrease in the molar ratio of $\mathrm{Si} / \mathrm{Ti}$ in gel from 40 to 10 . However, the catalytic activity and selectivity were decreased with a continuous decrease in Si/Ti. Excellent filtration performance of the in situ crystallized TS-1/CNFs composite was still maintained with varying the $\mathrm{Si} / \mathrm{Ti}$ ratio. 


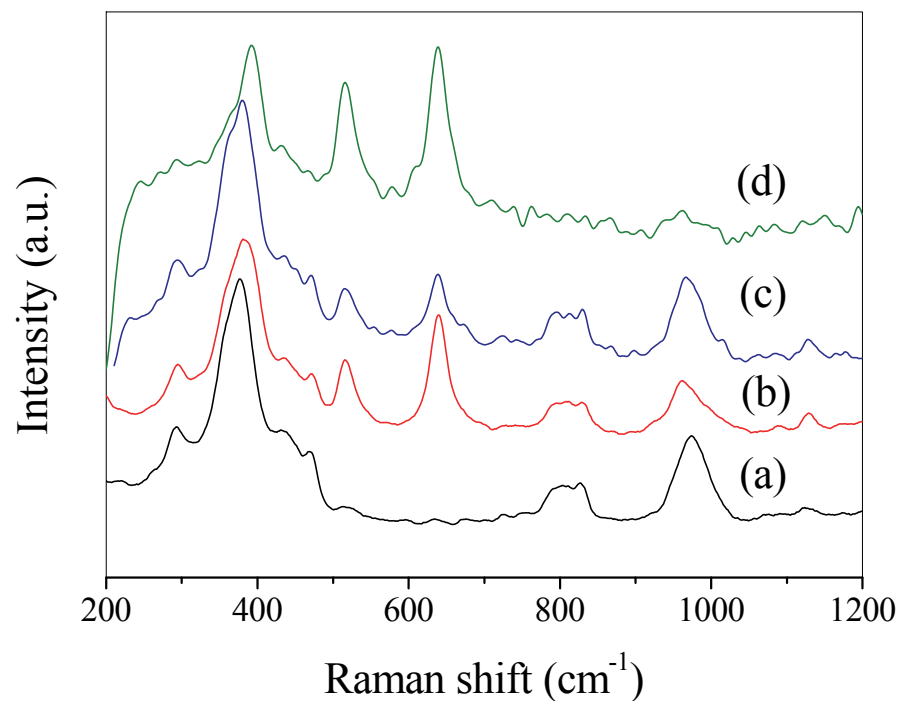

Fig. 7. Raman spectra of TS-1/CNF composites after removing CNFs.

(a) Blended TS-1/CNFs (Si/Ti=40); (b) In-situ crystallized TS-1/CNFs (Si/Ti=40);

(c) In-situ crystallized TS-1/CNFs (Si/Ti=10); (d) In-situ crystallized TS-1/CNFs (Si/Ti=5).

From the results of UV-Vis (Fig. 6) and Raman (Fig. 7) spectroscopy, it can be convinced that the MFI structure of TS-1 and the inclusion of Ti species in lattice are existent indeed in the TS-1/CNFs composites crystallized under different Si/Ti ratios. Meanwhile, the bands at $280 \mathrm{~nm}$ and $330 \mathrm{~nm}$ on the UV-Vis spectra in Fig. 6c-d are evident especially for the sample of $\mathrm{Si} / \mathrm{Ti}=5$, suggesting the generation of non-framework Ti species. The Raman bands of anatase particles are also observable at 397, 515 and $638 \mathrm{~cm}^{-1}$ in Fig. 7c-d.

In order to ascertain the lattice Ti content in each TS-1 samples with different Si/Ti ratios, the intensity of $960 \mathrm{~cm}^{-1}$ band on FT-IR spectra was normalized on the basis of the $455 \mathrm{~cm}^{-1}$ band, which is assigned to structure-insensitive $\mathrm{Si}-\mathrm{O}$ bending mode of tetrahedral $\mathrm{SiO}_{4}$ units. ${ }^{19}$ The results of $\mathrm{I}_{960} / \mathrm{I}_{455}$ were given in Table 2, where the value of Si/Ti ratio in solid TS-1 particles has been derived from XRF results.

\begin{tabular}{llll}
\hline Sample & $\mathrm{Si} / \mathrm{Ti}$ in gel & $\mathrm{Si} / \mathrm{Ti}$ in solid & $\mathrm{I}_{960} / \mathrm{I}_{455}$ \\
\hline $\begin{array}{l}\text { Blended } \\
\text { TS-1/CNFs after CNFs removal }\end{array}$ & 40 & 44.9 & 0.38 \\
$\begin{array}{l}\text { In-situ crystallized } \\
\text { TS-1/CNFs after CNFs removal }\end{array}$ & 40 & 61.7 & 0.30 \\
$\begin{array}{l}\text { In-situ crystallized } \\
\text { TS-1/CNFs after CNFs removal }\end{array}$ & 10 & 42.8 & 0.49 \\
$\begin{array}{l}\text { In-situ crystallized } \\
\text { TS-1/CNFs after CNFs removal }\end{array}$ & 5 & 21.3 & 0.36 \\
\hline
\end{tabular}

Table 2. Intensity ratio of $\mathrm{I}_{960} / \mathrm{I}_{455}$ in TS-1/CNFs composites with different $\mathrm{Si} / \mathrm{Ti}$ ratios.

As listed in Table 2, the Si/Ti ratios in solid are higher than those in gel, in accordance with the general rule followed in TS-1 synthesis. ${ }^{36}$ The value of Si/Ti in solid for the in situ 
crystallized sample is larger than that for the blended one with the same Si/Ti ratio in gel at 40. Clearly, the addition of CNFs into the gel has hindered the inclusion of Ti ions into the solid TS-1 particles. With respect to the ratio of $\mathrm{I}_{960} / \mathrm{I}_{455}$, lower value for the in situ crystallized TS- 1 was found than that of the blended one, indicating less content of Ti in the lattice of the in situ crystallized TS-1.19 With increasing the Si/Ti ratio in gel to 10 for the synthesis of in situ crystallized TS-1, a higher ratio of $\mathrm{I}_{960} / \mathrm{I}_{455}$ was attained, even exceeding the corresponding value of the blended TS- 1 whose $\mathrm{Si} / \mathrm{Ti}$ in gel is equal to 40 . The $\mathrm{I}_{960} / \mathrm{I}_{455}$ decreased at the $\mathrm{Si} / \mathrm{Ti}$ ratio of 5 .

Obviously, the incorporation of Ti into the lattice of TS-1 is affected by CNFs that is the primary reason for the decrease of the catalytic activity and selectivity. Furthermore, the formation of non-framework $\mathrm{Ti}$ species can also render the catalytic property worse. However, it should be pointed out that although the presence of CNFs in the synthesis gel can alter to some extent the proper circumstance for gestating perfect TS- 1 crystallites, there still would be measures capable of modifying the synthesis system. For example, it has been reported that a kind of Ti-rich TS-1 catalysts free of extra-framework Ti species was developed by using different ammonium salts as crystallization-mediating agent and a great increase in the catalytic activities in some cases was achieved as expected..$^{19}$ In view of the underlying principle proposed in the example, an attempt at counteracting the undesirable effect of CNFs while synthesizing TS-1 is undertaking in our laboratory.

\section{Conclusions}

TS-1/CNFs composites synthesized by in situ crystallization and mechanical blending methods show excellent filtrating performance. The large dimensions and macroporous structure of the composites constructed by firmly integrating TS-1 crystallites with CNFs can significantly improve the filtration efficiency. However, the introduction of CNFs into the synthesis gel before the crystallization of TS- 1 can inhibit the incorporation of Ti ions into the lattice of TS-1, resulting in low catalytic activity and selectivity of the TS-1/CNFs composite catalysts in cyclohexanone ammoximation. Furthermore, the presence of CNFs during TS-1 crystallization especially in the case of high $\mathrm{Si} / \mathrm{Ti}$ ratio in the gel can give rise to the generation of $\mathrm{TiO}_{2}$ (anatase) particles and hexa-coordinated titanium species, which can deteriorate the catalytic performance of TS-1. In contrast, the catalytic behavior of pure TS-1 is basically preserved in the blended TS-1/CNFs composite catalyst. Therefore, the blended composite catalyst seems to be more promising than the in situ crystallized one towards industrial applications.

\section{Acknowledgements}

The authors are grateful to the financial supports from the project of NSFC-20518001/RGCN_HKUST620/05, international cooperation project of Chinese Ministry of Science and Technology (2007DFC61690), 111 project of Chinese Education Ministry (B08021), and opening project of State Key Laboratory of Chemical Engineering (SKL-ChE-08C05).

\section{References}

Perego, C.; Carati, A.; Ingallina, P.; Mantegazza, M. A.; Bellussi, G. Production of titanium containing molecular sieves and their application in catalysis. Appl. Catal., A 2001, 221, 63-72. 
Saxena, S.; Basak, J.; Hardia, N.; Dixit, R.; Bhadauria, S.; Dwivedi, R.; Prasad, R.; Soni, A.; Okram, G. S.; Gupta, A. Ammoximation of cyclohexanone over nanoporous TS-1 using UHP as an oxidant. Chem. Eng. J. 2007, 132, 61-66.

Zhong, Z. X.; Xing, W. H.; Liu, X.; Jin, W. Q.; Xu, N. P. Fouling and regeneration of ceramic membranes used in recovering titanium silicalite-1 catalysts. J. Membr. Sci. 2007, 301, 67-75.

Li, G.; Jin, C. Z.; Wang, X. S. The synthesis and application of a titanium silicalite composite catalyst. CN Patent 1554 483, 2004.

Schodel, R.; Birke, P.; Geyer, R.; Kraak, P.; Muller, W.; Neubauer, H. D.; Pester, R.; Vogt, F.; Wendlandt, K. P. Oxidation catalysts, US Patent 5736 479, 1998.

Yip, A. C. K.; Lam, F. L. Y.; Hu, X.; Li, P.; Yuan, W. K. Study on the synthesis of clay-based titanium silicalite-1 catalytic composite. Ind. Eng. Chem. Res. 2009, 48, 5266-5275.

Birke, P.; Kraak, P.; Pester, R.; Schodel, R.; Vogt, F. Carbon supported TS-1 catalyst. Stud. Surf. Sci. Catal. 1994, 83, 425-432.

De Jong, K. P.; Geus, J. W. Carbon nanofibers: catalytic synthesis and applications. Catal. Rev. Sci. Eng. 2000, 42, 481-510.

Chinthaginjala, J. K.; Seshan, K.; Lefferts, L. Preparation and application of carbon-nanofiber based microstructured materials as catalyst supports. Ind. Eng. Chem. Res. 2007, 46, 3968-3978.

Tessonnier, J. P.; Rosenthal, D.; Hansen, T. W.; Hess, C.; Schuster, M. E.; Blume, R.; Girgsdies, F.; Pfander, N.; Timpe, O.; Su, D. S.; Schlogl, R. Analysis of the structure and chemical properties of some commercial carbon nanostructures. Carbon 2009, 47, 1779-1798.

Pinilla, J. L.; Lázaro, M. J.; Suelves, I.; Moliner, R.; Palacios, J. M. Characterization of nanofibrous carbon produced at pilot-scale in a fluidized bed reactor by methane decomposition. Chem. Eng. J. 2010, 156, 170-176.

Zhao, Q.; Li, P.; Li, D. Q.; Zhou, X. G.; Yuan, W. K.; Hu, X. J. Synthesis and characterization of titanium silicate-1 supported on carbon nanofiber. Microporous and Mesoporous Mater. 2008, 108, 311-317.

Fejes, P.; Nagy, J. B.; Halasz, J.; Oszko, A. Heat-treatment of isomorphously substituted ZSM-5 zeolites and its structural consequences: An X-ray diffraction, 29Si MASNMR, XPS and FT-IR spectroscopy study. Appl. Catal., A 1998, 175, 89-104.

Shibata, M.; Gabelica, Z. Synthesis of MFI titanosilicates from methylamine-TPABr media. Zeolites 1997, 19, 246-252.

Zhao, Q.; Li, P.; Li, D. Q.; Zhang, L. M.; Zhou, X. G.; Yuan, W. K.; Hu, X. J. Filtration and catalytic performance of blended TS-1/CNF composite catalyst. J. Chem. Ind. Eng. (China) 2008, 59, 2000-2006.

Li, P.; Zhao, T. J.; Zhou, J. H.; Sui, Z. J.; Dai, Y. C.; Yuan, W. K. Characterization of carbon nanofiber composites synthesized by shaping process. Carbon 2005, 43, 2701-2710.

Heertjes, P. M.; Zuideveld, P. L. Clarification of liquids using filter aids. Powder Tech. 1978, 19, 17-64.

Wenmakers, P. W. A. M.; van der Schaaf, J.; Kuster, B. F. M.; Schouten, J. C. Enhanced liquid-solid mass transfer by carbon nanofibers on solid foam as catalyst support. Chem. Eng. Sci. 2010, 65, 247-254.

Fan, W.; Duan, R. G.; Yokoi, T.; Wu, P.; Kubota, Y.; Tatsumi, T. Synthesis, crystallization mechanism, and catalytic properties of titanium-rich TS-1 free of extraframework titanium species. J. Am. Chem. Soc. 2008, 130, 10150-10164. 
Serrano, D. P.; Uguina, M. A.; Ovejero, G.; van Grieken, R.; Camacho, M. Evidence of solidsolid transfomations during the TS-1 crystallization from amorphous wetness impregnated $\mathrm{SiO}-\mathrm{TiO}_{2}$ xerogels. Microporous Mater. 1996, 7, 309-321.

Fan, W.; Fan, B.; Shen, X.; Li, J.; Wu, P.; Kubota, Y.; Tatsumi, T. Effect of ammonium salts on the synthesis and catalytic properties of TS-1. Microporous Mesoporous Mater. 2009, 122, 301-308.

Li, G.; Wang, X. S.; Guo, X. W.; Liu, S.; Zhao, Q.; Bao, X. H.; Lin, L.W. Titanium species in titanium silicalite TS-1 prepared by hydrothermal method. Mater. Chem. Phys. 2001, 71, 195-201.

Zecchina, A.; Bordiga, S.; Lamberti, C.; Ricchiardi, G.; Scarano, D.; Petrini, G.; Leofanti, G.; Mantegazza, M. Structural characterization of Ti centres in Ti-silicalite and reaction mechanisms in cyclohexanone ammoximation. Catal. Today 1996, 32, 97-106.

Khouw, C. B.; Davis, M. E. Catalytic activity of titanium silicalites synthesized in the presence of alkali metal and alkaline earth ions. J. Catal. 1995, 151, 77-86.

Van der Pol, A. J. H. P.; Van Hooff, J. H. C. Parameters affecting the synthesis of titanium silicalite-1. Appl. Catal., A 1992, 92, 93-111.

Van der Pol, A. J. H. P.; Verduyn, A. J.; Van Hooff, J. H. C. Why are some titanium silicalite1active and others not? Appl. Catal., A 1992, 92, 113-130.

Bhaumik, A.; Samanta, S.; Mal, N. K. Highly active disordered extra large pore titanium silicate. Microporous Mesoporous Mater. 2004, 68, 29-35.

Taramasso, M.; Perego, G.; Notari, B. Preparation of porous crystalline synthetic material comprised of silicon and titanium oxides. US Patent 4410 501, 1983.

Ricchiardi, G.; Damin, A.; Bordiga, S.; Lamberti, C.; Spano, G.; Rivetti, F.; Zecchina, A. Vibrational structure of titanium silicate catalysts. A spectroscopic and theoretical study. J. Am. Chem. Soc. 2001, 123, 11409-11419.

Reddy, J. S.; Kumar, R. Synthesis, characterization, and catalytic properties of a titanium silicate, TS-2, with MEL structure. J. Catal. 1991, 130, 440-446.

Wang, X. S.; Guo, X. W. Synthesis, characterization and catalytic properties of low cost titanium silicalite. Catal. Today 1999, 51, 177-186.

Huybrechts, D. R. C.; Buskens, P. L.; Jacobs, P. A. Physicochemical and catalytic properties of titanium silicalites. J. Mol. Catal. 1992, 71, 129-147.

Blasco, T.; Camblor, M. A.; Corma, A.; Perez-Pariente, J. The state of Ti in titanoaluminosilicates isomorphous with zeolite $\beta$. J. Am. Chem. Soc. 1993, 115, 11806-11813.

Deo, G.; Turek, A. M.; Wachs, I. E.; Huybrechts, D. R. C.; Jacobs, P. A. Characterization of titania silicates. Zeolites 1993, 13, 365-373.

Gao, H. X.; Lu, W. K.; Chen, Q. L. Characterization of titanium silicalite-1 prepared from aqueous $\mathrm{TiCl}_{3}$. Microporous Mesoporous Mater. 2000, 34, 307-315.

Gontier, S.; Tuel, A. Synthesis of titanium silicalite-1 using amorphous $\mathrm{SiO}_{2}$ as silicon source. Zeolites 1996, 16, 184-195. 


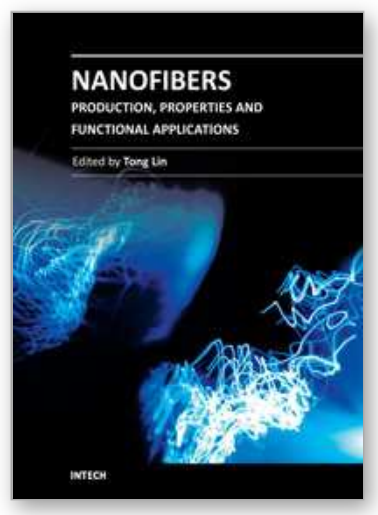

\author{
Nanofibers - Production, Properties and Functional Applications \\ Edited by Dr. Tong Lin
}

ISBN 978-953-307-420-7

Hard cover, 458 pages

Publisher InTech

Published online 14, November, 2011

Published in print edition November, 2011

As an important one-dimensional nanomaterial, nanofibers have extremely high specific surface area because of their small diameters, and nanofiber membranes are highly porous with excellent pore interconnectivity. These unique characteristics plus the functionalities from the materials themselves impart nanofibers with a number of novel properties for advanced applications. This book is a compilation of contributions made by experts who specialize in nanofibers. It provides an up-to-date coverage of in nanofiber preparation, properties and functional applications. I am deeply appreciative of all the authors and have no doubt that their contribution will be a useful resource for anyone associated with the discipline of nanofibers.

\title{
How to reference
}

In order to correctly reference this scholarly work, feel free to copy and paste the following:

Qian Zhao, Shiyuan Zhang, Ping Li, Weikang Yuan, Alex Chikin Yip and Xijun Hu (2011). Filtration and Catalytic Behaviors of Titanium Silicate-1 Supported on Carbon Nanofibers for Cyclohexanone Ammoximation, Nanofibers - Production, Properties and Functional Applications, Dr. Tong Lin (Ed.), ISBN: 978-953-307-420-7, InTech, Available from: http://www.intechopen.com/books/nanofibers-production-properties-and-functionalapplications/filtration-and-catalytic-behaviors-of-titanium-silicate-1-supported-on-carbon-nanofibers-for-cyclohe

\section{INTECH}

open science | open minds

\section{InTech Europe}

University Campus STeP Ri

Slavka Krautzeka 83/A

51000 Rijeka, Croatia

Phone: +385 (51) 770447

Fax: +385 (51) 686166

www.intechopen.com

\section{InTech China}

Unit 405, Office Block, Hotel Equatorial Shanghai

No.65, Yan An Road (West), Shanghai, 200040, China

中国上海市延安西路65号上海国际贵都大饭店办公楼405单元

Phone: +86-21-62489820

Fax: +86-21-62489821 
(C) 2011 The Author(s). Licensee IntechOpen. This is an open access article distributed under the terms of the Creative Commons Attribution 3.0 License, which permits unrestricted use, distribution, and reproduction in any medium, provided the original work is properly cited. 